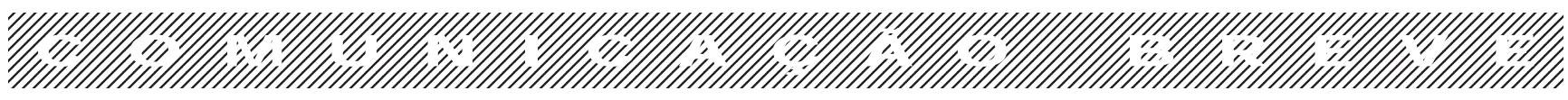

\title{
A mãe, seu filho hospitalizado e o brincar: um relato de experiência
}

\author{
Maria de Fátima Pinheiro da Silva Junqueira \\ Fundação Oswaldo Cruz
}

\begin{abstract}
Resumo
O presente relato baseia-se em um trabalho realizado nas enfermarias pediátricas do Instituto Fernandes Figueira/FIOCRUZ, Rio de Janeiro, que teve o objetivo de observar e fortalecer o vínculo entre a mãe e seu filho hospitalizado através do brincar. O trabalho prático é descrito a partir de seu embasamento teórico. Para finalizar, algumas reflexões são apresentadas acerca do papel do brincar na relação mãe-filho no âmbito hospitalar.

Palavras-chave: relação mãe-filho, hospitalização infantil, brincar.
\end{abstract}

\begin{abstract}
Mother, hospitalized child and playing: an experience report. The present report is based on a work accomplished in the pediatric wards of the Instituto Fernandes Figueira/FIOCRUZ, Rio de Janeiro, aiming to observe and to fortify the attachment between mother and her hospitalized child, through the act of playing. The practical work is described established on its theoretical basis. Some considerations on the role of playing in the mother-child relationship under a hospital context are presented.
\end{abstract}

Key words: mother-child attachment, child hospitalization, playing.

$\mathrm{O}$ relato aqui apresentado baseia-se em uma experiência de trabalho que se deu nas enfermarias pediátricas do Instituto Fernandes Figueira/FIOCRUZ no período de dezoito meses (1999/2000). Tal experiência teve como ponto de partida o interesse em realizar um estudo acerca da relação entre a atividade lúdica promovida pelo "Saúde e Brincar - Programa de Atenção Integral à Criança Hospitalizada”" e o vínculo existente entre a mãe e seu filho hospitalizado ${ }^{2}$. O Saúde e Brincar tem como principais objetivos levar o brincar às enfermarias pediátricas e analisar os efeitos da atividade lúdica neste ambiente. Este programa visa a elaboração de uma proposta de prevenção primária em populações de risco para a saúde mental.

Cabe ressaltar que a hospitalização da criança leva-a a se confrontar com um estado de desamparo, ao perceber sua fragilidade corporal que resultou no adoecimento, originando reações diversas tais como regressões, estados depressivos, fobias e transtornos de comportamento em geral (Ajuriaguerra, 1973). Além disso, ela se vê afastada de seu cotidiano, ficando numa posição de passividade e desconforto que geralmente lhe parece incompreensível. Dessa forma, o brincar se insere nesse contexto como uma tentativa de transformar o ambiente das enfermarias, proporcionando condições psicológicas melhores para as crianças e adolescentes internados.

O brincar facilita o acesso à atividade simbólica e a elaboração psíquica de vivências do cotidiano infantil. Através dos jogos simbólicos, a realidade externa pode ser assimilada à realidade interna, nesse caso específico, auxiliando a criança a lidar com o seu adoecer e a hospitalização. Podemos dizer que a criança se apropria da experiência dolorosa através do brincar, esse espaço de ilusão situado entre o real e a fantasia. Ela passa a ser sujeito e não somente objeto da experiência. (Santa Roza, 1993; Winnicott, 1975).

Nesses seis anos de desenvolvimento do trabalho com um enfoque na criança e o brincar, uma questão em relação à mãe, que ao acompanhar seu filho durante a hospitalização também se percebe "internada", foi surgindo juntamente com uma demanda para lançar um olhar para os aspectos relacionados ao vínculo entre mãe e filho. No decorrer da internação, a mãe (ou figura substituta) aparece como figura de apoio à criança, mas que, por sua vez, também vivencia medos frente à hospitalização. Mesmo a angústia de morte vivida pela cri- 
ança é também sentida por ela, sendo que sua reação frente à hospitalização desempenha um papel fundamental na forma como a criança lida com a sua própria situação de internação no hospital. Assim sendo, a criança, quando hospitalizada, além das questões referentes ao seu adoecimento e ao seu afastamento do ambiente doméstico, tem de lidar com a problemática relativa ao vínculo estabelecido entre ela e sua mãe, o qual geralmente fica fragilizado.

Acreditamos na importância de um vínculo forte entre mãe e filho como uma forma de auxílio à recuperação da criança, na busca de um bem-estar. Mas será possível para esta mãe proporcionar uma base segura para seu filho, quando ela própria se encontra fragilizada e, de certa forma, internada com ele? Será que o brincar também não pode ser para a mãe um caminho para a elaboração da doença de seu filho e um meio para fortalecer esse vínculo?

\section{Objetivos do trabalho}

A partir da perspectiva mais ampla do Programa Saúde e Brincar, o trabalho com um enfoque no vínculo entre a mãe e seu filho hospitalizado teve o objetivo de lançar, através do brincar, um olhar atento e cuidadoso sobre esse vínculo. Buscou-se, assim, compreender de que forma o brincar poderia intervir nesse vínculo como um agente facilitador, como um espaço potencial capaz de proporcionar um fortalecimento da relação mãe-filho. Cabe ressaltar que, acima de tudo, buscou-se fortalecer esta relação.

Como mencionado anteriormente, a hospitalização pode se configurar como um evento estressante e mesmo traumático, quando não levada em consideração a complexa dimensão humana (Santa Roza, 1997). Oliveira (1997), a partir de uma pesquisa realizada com crianças hospitalizadas, formulou algumas categorias acerca do que havia ouvido das próprias crianças. As representações de doença se formularam como: dor, evento concreto, modificação do comportamento habitual, ameaça à integridade física, medo/vivência de morte, suplício/tortura, culpa/castigo. Já as representações do hospital se apresentaram como: desconhecido/estranho, sem possibilidade de atividades ao ar livre, proibição de brincar, anonimato, evita a morte em casa, lugar de torturas/suplícios/ agressões físicas com intenções punitivas, solidão/tristeza/ saudade. Em contrapartida, as representações de família e amor parental se configuraram como: família de tipo nuclear, a mãe em todos os eventos, o pai como alvo de amor, laços familiares extensivos. Tal estudo corrobora a nossa abordagem de como a hospitalização pode ser assustadora e ansiogênica para a criança, assim como a de que a presença da mãe (ou substituto) significa segurança e confiança em um momento particularmente difícil, tanto em seus aspectos físicos quanto emocionais.

Cabe ressaltar que a reação de uma criança frente à hospitalização depende de vários fatores, particularmente de suas vivências anteriores assim como as de sua família. Kudo e Pierri (1997) apontam os seguintes fatores como capazes de influenciar a reação de uma criança em uma situação de internação hospitalar: o tipo de vínculo afetivo mãe-filho es- tabelecido antes da internação, a personalidade da criança, tempo de duração da internação, atitude da equipe hospitalar e idade da criança. O autor sinaliza, pois, um conjunto de fatores que não podem ser esquecidos quando a criança e seus pais chegam a um hospital.

Levando-se em consideração que há uma dimensão vivencial na experiência de estar saudável e de adoecer, isto é, o fato de aspectos subjetivos encontrarem-se imbricados nessa experiência, torna-se necessário o acolhimento dos medos, desejos e ansiedades que possam se apresentar e que porventura façam parte do ilimitado mundo da fantasia na criança. Nesse sentido, no espaço da internação hospitalar é preciso se promover um aguçamento da escuta (Ceccim, 1997). Essa escuta se faz necessária tanto em relação à criança quanto em relação a sua mãe. O brincar, por se configurar como um espaço potencial onde questões podem ser revividas e elaboradas, apresenta-se como o espaço e o momento privilegiados para o exercício dessa escuta, em uma perspectiva de atenção integral à criança.

Em relação à brincadeira, importa ressaltar o fato de ela permitir que a criança desempenhe uma atividade generalizada, através de uma imitação ou repetição. Segundo Kishimoto (1992), desta forma a criança reproduz as relações que observa em seu meio, vivenciando simbolicamente diferentes papéis, o que possibilita o exercício de sua capacidade de generalização e abstração. O brincar também tem um espaço e tempo próprios e por isso apresenta uma ordem específica, já que, ao mesmo tempo em que ordena, ele é a própria ordem. Quando a criança brinca, ela delimita o espaço e o tempo da brincadeira, num jogo de "faz de conta" ordenado (Huizinga, 1980). E, nas palavras de Mitre (2000), “quando lidamos com uma clientela que tem sua rotina de vida desestruturada pela doença, o brincar aparece como uma possibilidade de organização desse caos” (p. 10). Elaborar os aspectos da enfermidade e de sua conseqüente internação é algo fundamental para a criança e sua mãe, e o brincar apresenta-se como um espaço apropriado para fazer falar sobre a singularidade do processo de adoecimento e de hospitalização.

Tratando do vínculo mãe-filho, Bowlby (1989) sinaliza que a relação entre a mãe e seu bebê se origina de certos comportamentos característicos, que se organizam promovendo um vínculo entre os dois. Pode-se dizer que o autor compreende o comportamento de cuidados, isto é, de apego a partir de uma abordagem etológica. A provisão de uma base segura por parte da mãe dependeria desse comportamento de apego. Refletindo a necessidade que a criança hospitalizada tem de encontrar uma base segura em sua mãe é que nos propusemos a trabalhar esse vínculo, tendo como referência o brincar estabelecido entre a mãe e seu filho. Isto porque a mãe é aquela que pode prover para a criança, além de uma base segura (Bowlby, 1984), um holding (Winnicott, 1960/ 1983; 1994) suficiente a seu desenvolvimento.

Para Winnicott (1994), a provisão ambiental fornecida pela mãe e que permite ao lactente a experiência de confiabilidade, pode ser designada pelo termo holding. Inicialmente, o holding implica o segurar físico do bebê, uma experiência cutânea na qual ele se sente sustentado e ampara- 
do fisicamente. Esse significado vai se ampliando à medida que o bebê cresce e que seu mundo vai se tornando mais complexo. Deixa de ser apenas o aspecto físico, passando a ser a forma total do relacionamento mãe-filho, em que este se sente protegido e amparado.

Ainda sobre o vínculo existente entre a mãe e seu filho, Maturana e Verden-Zöller (1993) postulam que a auto-identidade e a consciência de si mesmo (assim como a social) dependem da consciência corporal que, por sua vez, só se desenvolve através de um contato corporal íntimo com a mãe. Esse contato se dá através de uma convivência de aceitação mútua, de uma relação de confiança. A criança adquire condições de criar seu espaço psíquico e seu espaço relacional a partir desse contato corporal com a mãe, que aparece como um outro eu, instalando-se uma dinâmica social como uma dinâmica da mútua aceitação, isto é, de amor. A partir daí, os autores caracterizam a relação entre a mãe e seu bebê como uma relação baseada no brincar.

\section{O trabalho}

\section{As enfermarias}

Como mencionado anteriormente, realizamos o trabalho junto às mães e crianças internadas no IFF, especificamente nas Enfermarias Pediátricas e na Enfermaria de Doenças Infecto-Parasitárias-DIP, justamente por serem os locais onde se encontra a população prioritariamente atendida pelo Saúde e Brincar. O IFF caracteriza-se pelo atendimento a crianças graves, muitas vezes portadoras de doenças crônicas e de síndromes genéticas. Estes fatores implicam, geralmente, internações prolongadas, o que ocasiona mais ansiedade e medo tanto nas crianças quanto em seus acompanhantes, em sua maioria, as mães.

Mediante o quadro de hospitalização infanto-juvenil do IFF acima mencionado, fica mais fácil compreender a dinâmica das enfermarias, que se apresentam como um local onde há um clima quase permanente de muita tensão e extrema solicitação das equipes que acompanham os pacientes. As enfermarias encontram-se divididas em pequenos boxes, com dois leitos cada e poltronas reclináveis onde os acompanhantes (mães) ficam e dormem, por vezes, durante semanas ou meses. Apesar das divisórias, é possível observar o que se passa em outros boxes, desde procedimentos rotineiros até aqueles de emergência, incluindo ocasionais mortes. Nesse sentido, a angústia, o medo da morte, a dor em ver seu filho doente, a preocupação com o afastamento do lar, dos outros filhos e, porventura, do trabalho tornam-se presenças contínuas não só para as mães, mas também para seus filhos afetando, de algum modo, o vínculo entre eles.

A estada da mãe junto ao seu filho durante a internação é um direito assegurado por lei. Todos sabem da importância da presença da mãe para a recuperação da criança. No entanto, tratando-se especificamente do IFF com suas internações prolongadas devido à gravidade dos casos, é preciso levar em consideração o fato de que, muitas vezes, essas mães encontram-se exaustas e sem condições emocionais de cui- darem todo o tempo de seus filhos da maneira desejada e solicitada pela equipe. A maioria das mães não se ausenta, pois teme que algo aconteça com seus filhos durante esse período. Por outro lado, muitas vão ficando cada vez mais ansiosas e, freqüentemente, irritadiças. A criança percebe o estado da mãe e também se inquieta o que, por sua vez, mobiliza a equipe que vem acompanhando o pequeno paciente. Solicitadas a cuidarem mais de seus filhos elas acabam se sentindo inadequadas, incapazes, o que somente dificulta ainda mais a relação com a criança adoecida.

O relatado acima se apresenta como um quadro geral freqüente no dia-a-dia das enfermarias pediátricas do IFF. Isto sem mencionar os graves problemas sociais que essas mães enfrentam, tais como dificuldades com a moradia, o fato de, em sua maioria, morarem longe e não terem dinheiro para a passagem, a preocupação com os outros filhos que ficam sob os cuidados de parentes ou vizinhos e as faltas ao trabalho.

Em meio a essa rotina e fazendo parte dela, ocorre o trabalho do Saúde e Brincar duas tardes por semana. Cabe aqui ressaltar que a transformação que se dá na enfermaria durante o brincar chama a atenção, uma vez que as crianças saem da passividade muitas vezes requisitada pelo ambiente hospitalar e passam a ocupar o espaço de outra forma. A música e a brincadeira atraem o olhar das mães que muitas vezes se aproximam com seus filhos, ou aproveitam o momento para sair um pouco da enfermaria. Há, sem dúvida, uma alteração no ritmo das relações estabelecidas nesse ambiente. Neste momento também se torna possível observar o quanto essas mães necessitam ser ouvidas em suas angústias e dúvidas, uma vez que, informalmente, se aproximam de membros da equipe do Programa Saúde e Brincar buscando esclarecer dúvidas, falar de seu filho ou de si mesmas.

\section{A inserção nas enfermarias}

A nossa entrada especificamente nas enfermarias ocorreu basicamente a partir de dois momentos: triagem e setting do brincar. A triagem caracteriza-se por ser uma etapa realizada preferencialmente no período da manhã, nos dias em que é montado o setting do brincar para o atendimento das crianças. O objetivo geral é saber quais as crianças que podem participar do brincar, aquelas que se encontram restritas ao leito e outras que, porventura, não podem participar de nenhum tipo de atividade. A partir de uma conversa com os médicos responsáveis pelas crianças, também nos informamos a respeito das doenças, prognósticos, evolução do quadro, possíveis restrições, recomendações, estado geral da criança, relação com a equipe, estado emocional, dificuldades com a rotina hospitalar e o que mais eles puderem observar e nos transmitir.

Com a entrada na equipe do Programa, assumimos a realização da triagem pois, além de considerarmos as informações médicas de extrema relevância para a avaliação das crianças, percebemos ser este um momento propício para uma maior aproximação das mães. Assim sendo, esses períodos matinais também eram dedicados a apresentar o trabalho do Programa Saúde e Brincar para as crianças e mães internadas 
pela primeira vez no hospital, a conversar com as mães e a escutá-las.

Durante o setting do brincar, procurávamos também estar com as mães e as crianças, observando o vínculo entre a mãe e seu filho e as peculiaridades promovidas pelo brincar, posto que na parte da manhã, também podíamos observá-los, só que em outro momento: sem o brincar e em um período em que geralmente se dá a maior parte dos procedimentos médicos, diversas vezes dolorosos e invasivos.

Interessante salientar que com a nossa entrada no trabalho com um olhar atento para as mães e seus filhos foram, aos poucos, surgindo demandas não somente dos membros do Programa, mas também da equipe médica e até mesmo do Serviço Social. Durante a triagem, os médicos passaram a falar mais das mães e a solicitar que as víssemos no decorrer do brincar. Esta solicitação já vinha se dando em relação a algumas crianças, mas em relação às mães parecia ser algo novo. Inclusive, a equipe médica (não uniformemente) adotou a postura de, em alguns casos, estimular a ida da criança para o setting pensando também na necessidade da mãe.

Paralelamente à demanda dos profissionais, intensificouse a demanda das próprias mães que, além de solicitarem os membros do Programa para conversas, também passaram a freqüentar mais o setting do brincar. Todas as mães eram convidadas a participar e, aos poucos, mesmo as mães cujos filhos dormiam na hora do brincar começaram a participar das atividades quer fosse desenhando, jogando ou sentando na mesa para conversar e olhar as crianças brincando.

Devemos salientar que o fato de algumas mães nos procurarem para conversar e, por vezes, desabafar, sinaliza o grau de angústia que a hospitalização de um filho provoca. Provavelmente, por ser o Saúde e Brincar um trabalho que quebra a rotina hospitalar, trazendo um novo olhar para a criança adoecida e uma preocupação com aspectos outros que não somente as questões físicas e orgânicas, as mães encontram aí um espaço para se colocarem sem se sentirem cobradas e exigidas (o que em alguns momentos pode ser imprescindível). Elas, assim como seus filhos, têm a necessidade de serem olhadas e cuidadas, até para que possam cuidar melhor de suas crianças.

\section{Algumas reflexões}

No decorrer desse período, acompanhamos de forma mais próxima oito pares mães-filhos internados nas enfermarias do IFF/FIOCRUZ, os quais se mostraram ilustrativos do trabalho lá desenvolvido. A título de organização para a apresentação, dividimos os oitos casos em três grupos: quatro crianças com distúrbios neurológicos, três crianças com doenças crônicas e uma criança com um quadro infeccioso agudo. A divisão em subgrupos deveu-se às singularidades que cada um apresentou, tendo-se levado em consideração os diferentes tipos de patologia e seus prognósticos. O acompanhamento desses casos nos levou a algumas reflexões acerca da função do brincar para as mães que acompanham os filhos em casos de hospitalização e, conseqüentemente, para o vínculo estabelecido entre ambos. Nesse sentido, pareceu-nos que:
1. O brincar aparece como sinal de saúde na perspectiva das mães. Dessa forma, ver os filhos brincando permitiu às mães sentirem-se menos angustiadas podendo, inclusive, relacionarem-se de maneira mais confiante com as crianças. Isto se mostrou com mais evidência nos casos nos quais as crianças eram portadoras de doenças crônicas. O fato de brincarem representava para as mães um aspecto saudável e preservado da doença. Este aspecto também pode ser observado nos pares envolvendo crianças com neuropatias. Esse aspecto saudável pode ser compreendido a partir de Mitre (2000), que em seu estudo conclui que através do brincar a criança se vê possibilitada de transpor as limitações impostas pela doença e pela hospitalização. Dessa forma, o brincar revela um aspecto saudável da criança, o qual pode ser percebido pela mãe que, por sua vez, também se sente menos ansiosa. Além disso, o fato de o brincar proporcionar o estabelecimento de relações de confiança com outras crianças, mas também com os adultos, incluindo a própria mãe (Mitre, 2000).

2. O brincar se estabelece como uma outra possibilidade de a mãe se comunicar e relacionar com seu filho, que não somente a perspectiva da doença. O aspecto saudável evidenciado com o brincar pareceu facilitar o resgate de uma relação não tão impregnada pela doença. Para Cañeque (1993) o brincar estimula uma ação religante, isto é, uma ação que torna a unir. Nesse sentido propicia a ligação da história pessoal de cada um com a história da comunidade como um todo, estimulando as conexões entre as experiências passadas. Constatamos, então, que o brincar tem, como uma de suas funções, o fato de agir como um fator de ativação e de estruturação das relações humanas. No caso da criança hospitalizada, essa ação religante é fundamental para a preservação de um vínculo saudável e seguro entre mãe e filho.

3. As mães de crianças com internações prolongadas e que permaneciam no hospital quase que diretamente tinham a necessidade de ficarem sós, sem o filho, até mesmo para poder estabelecer relações de maior qualidade tanto com a própria criança, quanto com a equipe que a atendia. O trabalho do Saúde e Brincar, para algumas mães, cumpria a função de permitir-lhes se ausentar da enfermaria sabendo que seu filho encontrava-se ocupado com uma atividade que lhe é própria. Como aponta Mitre (2000), “O acompanhante, em geral a mãe, também se interna junto com esta criança e acaba por sentir-se ‘aprisionado’ num ambiente que às vezes parece tão distante da vida cotidiana” (p. 48).

4. Especificamente nos casos em que a criança é portadora de algum distúrbio neurológico, o brincar assumia o papel de diluir qualquer tipo de diferença acarretada pela patologia, permitindo à mãe perceber seu filho aceito, olhado e respeitado como qualquer outra criança e, conseqüentemente, ela própria aceita, sem discriminações. Huizinga (1980), autor de uma das obras mais importantes sobre o jogo, aponta para o caráter universal desse fenômeno, já que está presente em todas as formas de organização social. Temos então que o brincar, por sua característica de universalidade, apresenta-se como uma linguagem comum a todos, com a comunicação se dando através das brincadeiras e das relações aí estabelecidas. 
5. Para as mães, particularmente aquelas que brincavam mesmo que separadamente dos filhos, o brincar funcionava como um espaço de escoamento das ansiedades. Na fala de uma mãe: "Sem vocês eu não conseguiria ficar aqui” (sic). Cabe ressaltar que o termo brincar origina-se do latim vinculum, que significa união, laço. Brincar, então, é uma forma de criar e fortalecer vínculos, sendo fundamental para a mãe e seu filho. Como este fenômeno favorece a criação de alianças entre as próprias crianças, entre estas e seus acompanhantes e a equipe (Mitre, 2000), a promoção de um brincar dentro de enfermarias pediátricas proporciona relações de maior qualidade entre os envolvidos no processo de hospitalização de uma criança.

\section{Referências}

Ajuriaguerra, J. (1973). Manual de Psiquiatria Infantil. Barcelona: Toray-Masson. Bowlby, J. (1984). Apego. São Paulo: Martins Fontes.

Bowlby, J. (1989). Uma base segura. Porto Alegre: Artes Médicas.

Cañeque, H. (1993). Juego e vida. Buenos Aires: Atheneo.

Ceccim, R. (1997). Criança hospitalizada: a atenção integral como uma escuta à vida. In R. B. Ceccim \& P. R. A. Carvalho (Orgs.), Criança hospitalizada: atenção integral como escuta à vida (pp. 27-41). Porto Alegre: UFRGS. Huizinga, J. (1980). Homo ludens. São Paulo: Perspectiva.
Kishimoto, T. (1992). A importância do jogo para a educação infantil. Cadernos de Terapia Ocupacional da UFSCar, 3, 121-139.

Kudo, A., \& Pierri, S. (1990). Terapia ocupacional com crianças hospitalizadas. In A. Kudo, E. Marcondes, L. Lins, L.T. Moriama, M. L. L. G. Guimarães, R. C. T. P. Juliane, S. A. Pierri (Orgs.), Fisioterapia, Fonoaudiologia e Terapia Ocupacional em Pediatria (pp. 232-245). São Paulo: Sarvier.

Maturana, H., \& Verden-Zöller, G. (1993). Amor y juego: Fundamentos olvidados de lo humano. Santiago: Instituto de Terapia Cognitiva.

Mitre, R. M. de A. (2000). Brincando para viver: um estudo sobre a relação entre a criança gravemente adoecida e hospitalizada e o brincar. Dissertação de mestrado não-publicada, Instituto Fernandes Figueira/FIOCRUZ, Rio de Janeiro.

Oliveira, H. (1997). Ouvindo a criança sobre a enfermidade e a hospitalização. In R. B. Ceccim \& P. R. A. Carvalho (Orgs.), Criança hospitalizada - atenção integral como escuta à vida (pp. 42-55). Porto Alegre: UFRGS.

Santa Roza, E. (1993). Quando brincar é dizer: a experiência psicanalítica na infância. Rio de Janeiro: Relume-Dumará.

Santa Roza, E. (1997). Um desafio às regras do jogo. In E. Santa Roza \& E. S. Reis (Orgs.), Da análise na infância ao infantil na análise (pp. 161-188). Rio de Janeiro: Contra Capa.

Winnicott, D. W. (1975). O brincar e a realidade. Rio de Janeiro: Imago. Winnicott, D. W. (1983). O ambiente e os processos de maturação. Porto Alegre: Artes Médicas. (Obra originalmente publicada em 1960).

Winnicott, D. W. (1994). Os bebês e suas mães. São Paulo: Martins Fontes.

Nota

1 Concebido e implantado em 1994 pela Dra. Eliza Santa Roza, médica e psicanalista de crianças.

2 Estudo realizado com o suporte do convênio FIOCRUZ/FAPERJ.

Maria de Fátima Pinheiro da Silva Junqueira é doutoranda em Saúde da Criança e da Mulher IFF/FIOCRUZ, mestre em Psicologia Clínica PUC-Rio, especialista em Psicologia Médica e Psicossomática IFF/FIOCRUZ, membro do Fórum do Círculo Psicanalítico do Rio de Janeiro (CPRJ) e Psicóloga pela PUC-Rio. Endereço para correspondência: Av. Epitácio Pessoa 2566/808, Bl. A, Lagoa, 22471-001, Rio de Janeiro, RJ. Telefone: (21) 3205.8137.E-mail:mf.junqueira@terra.com.br. 